\title{
PREPARATION OF THE LARGE BOWEL FOR SURGERY
}

\author{
By H. E. LockharT-Mummery, M.ChIR., F.R.C.S. \\ Surgeon, St. Mark's Hospital, London
}

The advances of surgical science and technique in the last decade have influenced all branches of surgery, and that of the large bowel is no exception. From the early days of abdominal surgery until a few years ago, the hazards of sepsis dominated the techniques of colon surgery. Thus the staged extra-peritoneal technique of colectomy first described by Paul in 1895 and modified by Mikulicz (IgO3) became for many years the accepted standard operation for colonic resection. Immediate anastomosis was attended by greater risks, and though attempts were made to overcome the risk of sepsis by the use of special techniques of closed ' aseptic' anastomosis, such methods had certain disadvantages and did not find universal favour.

The advent in recent years of drugs and antiblotic substances by means of which the hazards of sepsis could be largely eliminated has therefore brought about a considerable change in the choice of method for colon resection. It has allowed the technique of immediate open anastomosis to become the accepted method of restoring continulity after resection of the colon, with a mortality that continues yearly to decrease. The main advantage of this technique over the Paul-Mikulicz method is that by its use a more radical operation can often be done, as preservation of sufficient bowel and related mesentery to reach the surface is no longer necessary. Further advantages, to the patient particularly, lie in the avoidance of a colostomy, albeit a temporary one, and in having only to undergo one operation. An open anastomosis allows of accurate mucosa-to-mucosa suture of the two ends, with less risk of reactionary haemorrhage, leakage or later stenosis than by a closed method.

The main advantage of sterility of the bowel contents in such operations is the great reduction in the risk of peritonitis and wound sepsis and thus the greatly increased safety. There are, however, other less obvious advantages: First, the healing process in a stetile gut is more orderly, becomes firm earlier and results in less scarring; second, the degree of oedema at the suture-line during the healing phase is considerably reduced in the्छ sterile gut (Poth et al., 1945, 1948). There is thus far less obstruction to the lumen of the bowes in the post-operative phase, with less risk of dis 3 . tension and earlier return of normal bowel move $\omega$ movement. This reduction in inflammatory resw action and its sequelae results in a smoother post $+\vec{f}$ operative course and fewer early or late complica $\overrightarrow{0}$ tions.

It must be appreciated, however, that for im은 mediate open anastomosis in the colon to be safe $\overrightarrow{-}$ the bowel must be well prepared; that is free froms distension and gross faecal loading and with itsbacterial content reduced as much as possibde $\overrightarrow{0}$ Thus both antibacterial and mechanical prepara of tion are necessary; open anatstomosis without such preparation is certain to result in a higher mor tality and would bring the method into disrepute Further, the surgeon's technique during the opera-n tion must be meticulous; with particular care takeno to preserve the blood-supply to the ends of bowie? being joined and to avoid faecal contamination. AO well-prepared bowel is no excuse for any relaxation? of meticulous operative technique.

\section{Intestinal Antisepsis}

Before discussing the methods of teducing the bacterial content of the intestine; it will be of advantage to discuss briefly the properties re quired of an ideal antiseptic (Poth; 1952). First $\frac{O}{\not 2}$ it should be effective against all normal bacteriaf inhabitants of the bowel and should not lead to the overgrowth of resistant strains: Second, i should be of low systemic toxicity and poorly absorbed from the intestinal tract; so that side on effects are minimal or absent. Third, it should not be destroyed by digestive ferments and shoulक be capable of acting in the presence of a normal food and fluid intake. Fourth, it should noo adversely affect any structure or function of the intestinal tract or interfere with repair and healing $\mathbb{\complement}$ Other properties, such as solubility in water: palatability, rapidity of action and reasonable cost $\frac{0}{5}$ are desirable though less important. No com $\frac{0}{0}$ pound is yet known which fulfils all these de $\frac{\rho}{\mathbb{D}}$ 
siderata. Although attempts had been made for over 50 years to reduce and alter the bacterial flora of the intestine, mainly by dietary measures, little success was achieved until the advent first of the sulphonamides and, later, of the antibiotics. Both these drugs have been of great value and it is instructive to consider in what way they depart from the ideal.

\section{The Sulphonamides}

These compounds are bacteriostatic in their action; that is they act by inhibiting the multiplication of bacteria rather than by destroying them directly. They therefore take several days to produce a marked reduction in the count of intestinal bacteria, as viable organisms must be mechanically removed from the bowel by defaecation. Though all the sulphonamide compounds have a slight and selective action on intestinal bacteria, the first of the poorly absorbed ones to be tried was sulphaguanidine. It did not prove satisfactory both because its action seemed to be variable in different subjects and therefore unreliable, and because it was found to be ineffective in the presence of an ulcerating lesion of the bowel (Firor and Poth, 1941). In 194I, however, a much more effective compound was discovered in sulphasuxidine (Poth and Knotts, 194r) and two years later the yet more powerful compound sulphathalidine was introduced (Poth and Ross, 1943). Both of these proved highly effective against a wide range of intestinal bacteria although, like other sulphonamides, they fail to inhibit certain gram-positive cocci. Sulphasuxidine tends to produce a semi-fluid stool, whereas sulphathalidine, though having two to four times the bacteriostatic activity, does not markedly alter the character of the stools. A further unexplained difference between the two compounds is that there seems to be a definite antagonism between sulphathalidine and penicillin (whether given orally or by injection) so that sulphathalidine becomes ineffective. This antagonism does not exist between sulphasuxidine and penicillin (Poth et al., 1946).

Either of these sulphonamides may be used for intestinal sterilization without fear of side-effects, but sulphathalidine is the more powerful and in most cases is the one to be preferred. Under favourable conditions a reduction in the coliform flora of the bowel of 99.9 per cent. may be obtained, with a considerable reduction also in the number of clostridia and other organisms. Further, this low coliform count may be maintained for several weeks if necessary if the drug is continued. A suitable dose of sulphathalidine is 3 to $5 \mathrm{~g}$. twice daily (a larger dose of sulphasuxidine is necessary), and this should be given for at least five days pre- operatively and combined with some mechanical cleansing and emptying of the bowel; the latter should not be pushed to the extent of violent purgation for it appears that the antibacterial effect is reduced in the presence of diarrhoea. Sideeffects are minimal, but certain patients are sensitive to all sulphonamides and are unable to take even those of which only 5 per cent. is absorbed.

\section{The Antibiotics}

These compounds fall into two groups, those like penicillin and streptomycin which are bactericidal, that is rapidly and directly lethal to bacteria even in low concentration; and those like aureomycin, chloramphenicol or terramycin which are mainly bacteriostatic.

Penicillin was found to have no noticeable effect an the bowel flora as would be expected from its known properties.

Streptomycin, first isolated by Waksman in 1943, showed promise at first of being a powerful and effective intestinal antiseptic. When given orally ( $\mathrm{g}$. daily in divided doses) 95 per cent. can be recovered later from the faeces. It is very effective against coliform organisms and grampositive cocci, but less so against proteus and the anaerobic organisms. Its action in the intestine is rapid, resulting in the elimination of practically all bacteria within 24 to 36 hours. Unfortunately, resistance to streptomycin is achieved by most organisms almost equally rapidly and often to a marked degree, so that within 48 to 72 hours of starting the drug the bacterial count may return to, and even pass, the former level. Furthermore, should systemic infection by these organisms occur in the post-operative period, streptomycin is valueless in its treatment.

It is thus not surprising that streptomycin alone was not considered to be a satisfactory intestinal antiseptic, but it seemed possible that the combination of sulphathalidine plus streptomycin might prove very effective, as resistance to both would be less likely to develop. However, it was found that after 48 hours resistant variants still began to appear and hence it became the practice of many surgeons to give sulphathalidine for five to seven days and combine it with streptomycin for the last two days only (Spaulding et al., 1949). At the present time the advisability of giving oral streptomycin at all before an intestinal operation is a controversial subject. Several authorities (Poth, 1949; Lockwood et al., 1949) believe that there is little or nothing to be gained by so doing, except in patients who cannot take sulphonamides at all. Nevertheless, this view has not been universally accepted, and the regime outlined above has been in use at St. Mark's Hospital and many others for some years and has given very 
satisfactory results. The time factor, however, is most important, and if for any reason the operation is postponed, the streptomycin must not be continued.

Of the antibiotics introduced more recently; chloramphenicol has not proved of much value, probably because it is highly effective only against the coliform group of organisms.

Aureomycin and terramycin are both effective against a wide range of intestinal organisms, though proteus and resistant strains may soon grow out. They have, however, certain undesirable side-effects. Nausea, vomiting and troublesome diarrhoea not uncommonly follow treatment with either of these drugs, and the diarrhoea, often aggravated by an unpleasant anal pruritus, may persist for weeks after the drug is stopped; actual ulceration of the intestine has been reported following therapy with both these drugs, possibly due to infection by monilia. Further, they are both freely absorbed and respiratory infections with monilia and even septicaemia due to resistant staphylococci have occasionally been reported. Thus they cannot be regarded as satisfactory drugs for use as intestinal antiseptics.

The most effective antibiotic known for this purpose appears to be neomycin, first isolated by Waksman and Lechevalier in 1949. Though at the time of writing it is unfortunately not available in this country, very encouraging reports of its use have appeared in American literature (Poth et al., 1950; Poth, 1952). Given parenterally it is rather toxic, but given orally it is so poorly absorbed that side-effects are absent, though it does produce thin, loose stools. It is effective against all normal intestinal bacteria except that it does not inhibit aerobacter aerogenes in about ro per cent. of patients, nor has it any action against yeasts, which grow out in large numbers as soon as the bacteria have been eliminated. Neomycin is extremely rapid in its action and it appears that in the absence of obstruction it is possible to render the gastro-intestinal tract almost sterile in 12 to 24 hours, the total number of organisms being reduced to less than 100 per $\mathrm{g}$. of stool. The drug has been given for several consecutive weeks without any ill effects, and the stools have remained sterile. It therefore appears that bacterial resistance either does not occur or is extremely slow in doing so. Further, though the yeasts are not eliminated, no instance of ulceration in the intestine has yet been mentioned after the use of neomycin.

Because of the growth of aerobacter aerogenes in Io per cent. of patients, Poth (1952) recommends that in cases where preparation must continue for more than 24 hours, sulphathalidine should also be given to prevent the outgrowth of this organism.
However, he considers that normally only 24 hourso is necessary for satisfactory intestinal sterilization if neomycin is used. The recommended daily oral dose of neomycin is $0.1 \mathrm{~g}$. per kilo of body $\mathrm{C}_{\mathrm{C}}$ weight, divided into six parts and administered four-hourly (4 to $6 \mathrm{~g}$. daily is a usual dose).

A further use of neomycin which promises to beo of great value is for ultra-rapid sterilization of theo gut. If at operation a I per cent. solution of neomycin is injected through the wall of the bowel (several hundred cc. has been used) after, 45 minutes no organisms can be grown from that ${ }^{\text {s }}$ part of the gastro-intestinal tract. As intestinal $\overrightarrow{0}$ activity is slow to return after operation, the neo- $\overrightarrow{-}$ mycin is only slowly eliminated and the gut will remain sterile for several days. The potential valuę of this in emergency surgery, particularly where 3 resection of the gut proves to be necessary, needsin no emphasis, and it seems likely that the operative mortality and morbidity of these emergencies could thus be reduced.

\section{Intestinal Antiseptics and Vitamin Synthesis}

One of the functions of certain organisms in the intestinal tract appears to be the synthesis of $\triangle$ vitamins, notably several of the $B$ complex and? vitamin $K$. When effective intestinal antiseptics were first introduced it was feared that steriliza-con tion might often lead to deficiencies in these vitamins and particularly to prothrombin de ficiency due to lack of vitamin $\mathrm{K}$ and, indeed, some reports of alteration of prothrombin time followingo the use of oral streptomycin were published. However, in a recent paper after wide experience,, $\mathbb{\Omega}$ Poth (1952) reports that no instance of alteration $\overrightarrow{5}$ of bleeding, clotting or prothrombin times has 3 been seen in a large series carefully studied, nor? has there been any instance of post-operative haemorrhage in the same group of patients. It appears, therefore, that this danger has been exaggerated and that unless the patient has been for'some time on a grossly deficient diet no alteration. of prothrombin time is to be expected. Nor doesô it appear to be necessary to administer extra vita $\min B$ and $K$ while these antiseptics are being 0 given to a fit patient unless such treatment is pro- $>$ longed for many weeks or is accompanied by a을. deficient diet. A patient with established vitamin deficiencies who comes under treatment would best be treated with intramuscular vitamin 0 supplements.

\section{Unsolved Problems in Intestinal Antiseptics}

As far as present knowledge on the subject goes it appears that the fungi and yeasts in the intestinal tract are held in check by the bacteria, 0 even a small number of bacteria being sufficient too restrain their growth. The elimination of bacteria 
from the intestine, such as follows the use of neomycin and terramycin, allows the yeasts to grow out in considerable numbers. It was thought that the intestinal ulceration sometimes reported after the use of terramycin was due to such yeasts, yet no such complication has been shown to follow the use of neomycin so there appears to be another factor at work.

No substance yet known will eliminate bacteria and also inhibit the growth of yeasts, and the question arises as to whether such additional inhibition is desirable. It is possible that if such a substance were to be introduced the result might well be the production of further undesirable side effects rather than the achievement of perfect preparation. It has indeed been suggested that a resistant strain of non-pathogenic bacteria should be introduced orally when the powerful oral antibiotics are given, with the object of inhibiting the overgrowth of yeasts. Such methods would require careful and prolonged experimental appraisal before their introduction to clinical practice, as such wide departures from normal flora might well lead to more problems than they solved. It seems likely that in intestinal antisepsis it may be better to be content with good results than to seek for perfection. There is still much further research to be done on this subject and results will be awaited with interest.

\section{Mechanical and General Preparation}

Usually five to seven days are required to prepare a patient with a lesion of the colon for operation, though in cases with severe anaemia or protein deficiency or with a considerable degree of obstruction a longer time may be necessary.

\section{Diet}

This should be of maximal caloric and protein content but should not contain things likely to lead to residue in the colon and add bulk to the faeces. Extra vitamins $\mathrm{C}$ and of the $\mathrm{B}$ complex in large doses are usually advisable to ensure saturation before operation.

\section{Aperients}

For the first few days of preparation it is as well to give liquid paraffin in fairly large doses ( $\frac{1}{2}$ to I oz. daily in two parts, morning and evening) and combine it with an aperient. The nature of the latter may be varied according to the patient's normal habits and inclinations, and the dose should be sufficient to ensure a daily action without purging. The paraffin will help to soften the stools above any obstructive lesion and in this way help them to pass through and be evacuated. It is as well, however, to stop all such oily preparations for the last 48 hours before operation as otherwise the faeces may be rather too 'muddy' and adherent to the wall and it is more difficult to remove them by the last washout. Castor oil $\frac{1}{2} \mathrm{oz}$. may be given 24 to 48 hours before operation, and is useful in that it acts quickly and empties the small bowel as well as ensuring a good bowel action.

\section{Washouts}

Washouts are rather trying for a patient and in the absence of marked obstruction it is probably sufficient to give one thorough washout 12 hours before operation, continuing until the returning fluid is clear and ensuring that all fluid is siphoned back. For patients with more obstruction, washouts may be advisable daily or on alternate days through the period of preparation, finishing with one as above 12 hours before operation. Washouts must only be given at low pressure and considerable skill and patience is required of the nurse to ensure that the colon is clean and free of fluid. A rectal tube should be passed on the morning of the operation to drain away any fluid remaining in the bowel.

In patients with a completely annular obstructing growth such mechanical preparation may be remarkably ineffective even if carried out for two to three weeks. Such cases are sometimes best prepared by a preliminary transverse colostomy; this not only allows good preparation of the distake bowel but often produces a marked and rapid? improvement in the patient's general health and appetite. This staged procedure should certainly be considered in ' poor risk' patients with marked chronic obstruction and a simple decompression operation (transverse colostomy or caecostomy) is undoubtedly the one of choice in a case of acute obstruction of the colon, leaving the resection until two to three weeks later when both the patient and the bowel will be in better condition.

\section{Summary}

With the drugs at present available in this country optimum antibacterial preparation of the bowel can probably best be achieved by giving sulphathalidine for five days and streptomycin orally in addition for the last two days. There is still some difference of opinion as to whether the addition of streptomycin is really of value. Chloramphenicol, aureomycin and terramycin have no place in routine intestinal antisepsis. Neomycin is reported as being the most effective intestinal antiseptic yet discovered with no serious drawbacks, but it is not yet available in this country.

No alteration of prothrombin time need be anticipated even with efficient intestinal antisepsis and there is no necessity to give extra vitamin $K$ at the same time. 
Further unsolved problems in intestinal antisepsis are briefly discussed and a scheme for mechanical preparation of the bowel is suggested.

\section{BIBLIQGRAPHY}

FIROR, W. M., and POTH, E. J. (1941), Ann. Surg., 114, 663. LOCKWOOD, J. S., YOUNG, A. D., MCLEMORE, B., BRYANT, T. R., and STOJOWSKI, A. J. (1949), Ibid., 29, 14 PAUL, F. T. (1895), Liverpool Med.-Chir. F., 15, 374. MIKULICZ, J. vọ (1903), Arch. Klin. Chir., 69, 28. POTH, E. J. (1949), Mil. Surg., 104, 358. POTH, E. J. (1952), Western F. Surg., 60, 205.
POTH, E. J., FROMM, S. M., WISE, R. I., and HSIANG, C. M (1950), Texas Rep., 8, 353 .

POTH, E. J., and KNOTTS, F. L. (I94I), Proc. Soc. Exper.气 Biology of Med., 48 , 120 .

POTH, E. J., and RO'SS, C. A. (1943), Fed. Proc., 2, 89. PQTH, E. J., ROSS, C: A., and FERNANDEZ, E. B. (1945), , Surgery, 18, 529 .

POTH, E. J., MCNEILL, J. P., MANHOFF, L. J., KING, W6, B., and SINCLAIR, J. G. (I948), 'Sirg., Gynec., Obstet.,

POTH, E. J., WISE, R. I., and SLATTERY, M. P. (1946), Surgery, 20, 147 .

RIDDELL, M. I. (1952), Am. Y. Med. Sci., 223, 301.

SPAULLING, E. H.; MADAJEWSKI, D. S., ROWE, R. J., and $\frac{\bar{\omega}}{}$ BACQN, H. E. (1949), Y. Bact., 58, 279 .

WAKSMAN; S. A., and LECHEVALIER, H. A. (1949), Science, $\varrho$ ro9, 305 .

\title{
INTERMITTENT CLAUDICATION IN A CASE OF POLYCYTHEMIA VERA TREATED BY SYMPATHETIC NERVE BLOCK
}

\author{
By G. C. STEEL, F.F.A. (R.C.S.) \\ Anaesthetist, Hampstead General (Royal Free Group), Chelsea Hospital for Women and \\ Queen Charlotte's Maternity' Hospital
}

Intermittent claudication is recognized as one of the manifestations of vascular occlusion associated with Polycythemia Vera. These various forms of occlusion have been discussed by several writers including Ray and Forbes (1948), Horton and Brown (1929) and Norman and Allen (1937).

Brown and Giffin (1930) in a review of roo cases of Polycythemia Vera found six cases of claudication with demonstrable occlusion. As a result of treatment with phenylhydrazine and phlebotomy, the symptoms disappeared in three of these cases. They suggest that the operative factors are: firstly an organic narrowing of the small vessels: secondly anoxaemia caused by a reduction of the circulation rate.

Oppenheimer (1929) recognizes two types of case in which circulatory disturbances are found in the legs: those in which there is a functional or vasomotor disturbance, the vessels being patent and oscillometric readings normal: secondly those with actual occlusion of the vessels in which oscillometric readings are diminished or absent.

A case recently seen by us appears to show that the vasospastic and obliterative elements can coexist in this type of case: that the one superadded on to the other may be responsible for the disability: and that treatment of the former by nerve blocks can banish the claudication.

In March I95 I a man of 66, a gardener, was referred to the anaesthetic department for assess- ment of his suitability for nerve block treatme Nine months previously, during a successful coureof treatment for Polycythemia Vera, he had perienced a very sudden and sharp pain in his lefto calf. Whilst the rest of his symptoms had abated with the treatment, he was still handicapped by the severe cramp-like pain in this calf which came on after he had walked three to four hundred yards, $\overrightarrow{0}$ compelling him to rest until it passed off.

On examination, arterial pulsations could be felt in the inguinal region on either side. On the right, the popliteal, posterior tibial and dorsalis pedis arteries were palpable: on the left they could not be felt. The left foot was white and colders than the right one. Oscillometric readings taken at rest showed a normal deviation of the needle $\mathrm{e}$ over the usual range of pressures for calf and thigh on the right side. As expected those of the left calf were very poor: in addition, those for the left thigh were equally poor thus presenting an appa $r$ ently gloomy prognosis.

In spite of this, nerve block treatment was undertaken, six blocks of the lumber extraduralo space being done in seven days, with an interval of one day in the middle: $10 \mathrm{ml}$. of xylocaine per cent. was used in each instance.

The oscillometric readings during this period were of great interest. On the right they showed: the normal increase following a block. On the left, as will be seen, the calf readings showed no 